\title{
SHARP REDHEFFER-TYPE AND BECKER-STARK-TYPE INEQUALITIES WITH AN APPLICATION
}

\author{
Chao-Ping Chen And Neven Elezović
}

Abstract. In this paper, we give sharp Redheffer-type and Becker-Stark-type inequalities for trigonometric functions. As an application of Redheffer-type inequality, we improve the wellknown Yang Le inequality.

Mathematics subject classification (2010): 26D05.

Keywords and phrases: Trigonometric function, inequalities.

\section{REFERENCES}

[1] M. Abramowitz And I. A. Stegun (Eds.), Handbook of Mathematical Functions with Formulas, Graphs, and Mathematical Tables, National Bureau of Standards, Dover, New York, 1965.

[2] D. Aharonov and U. Elias, Improved inequalities for trigonometric functions via Dirichlet and Zeta functions, Math. Inequal. Appl. 16, 3 (2013), 851-859.

[3] G. D. Anderson, S.-L. Qiu, M. K. Vamanamurthy and M. Vuorinen, Generalized elliptic integral and modular equations, Pacific J. Math. 192 (2000), 1-37.

[4] G. D. Anderson, M. K. Vamanamurthy and M. Vuorinen, Conformal Invariants, Inequalities, and Quasiconformal Maps, New York, 1997.

[5] G. D. Anderson, M. K. Vamanamurthy And M. Vuorinen, Monotonicity of Some Functions in Calculus, Available at http://www.math.auckland.ac.nz/Research/Reports/Series/ 538.pdf.

[6] B. BAnjac, M. MAKRAGiĆ AND B. MALEŠEVIĆ, Some notes on a method for proving inequalities by computer, Results. Math. 69, 1 (2016), 161-176.

[7] M. BECKER AND E. L. STRAK, On a hierarchy of quolynomial inequalities for $\tan x$, Univ. Beograd. Publ. Elektrotehn. Fak. Ser. Mat. Fiz. No. 602-633 (1978), 133-138.

[8] B. A. Bhayo And J. SÁndor, On Jordan's, Redheffer's and Willker's inequality, Math. Ineq. Appl. 19, 3 (2016) 823-839.

[9] C.-P. Chen And W.-S. Cheung, Sharp Cusa and Becker-Stark inequalities, J. Inequal. Appl. 2011 (2011) 136, http://www . journalof inequalitiesandapplications . com/content/2011/1/ 136.

[10] C.-P. CHEN AND R. B. PARIS, Series representations of the remainders in the expansions for certain trigonometric functions and some related inequalities, I, Math. Inequal. Appl. 20, 4 (2017), 10031016.

[11] C.-P. Chen, J.-W. ZhaO AND F. QI, Three inequalities involving hyperbolically trigonometric functions, Octogon Math. Mag. 12, 2 (2004), 592-596.

[12] L. Debnath, C. Mortici And L. Zhu, Refinements of Jordan-Stečkin and Becker-Stark inequalities, Results Math. 67 (2015), 207-215.

[13] L. Debnath And C. J. Zhao, New strengthened Jordan's inequality and its applications, Appl. Math. Lett. 16 (2003), 557-560.

[14] H.-F. GE, New Sharp Bounds for the Bernoulli Numbers and Refinement of Becker-Stark Inequalities, J. Inequal. Appl. 2012, Article ID 137507, 7 pages.

[15] W. D. JiAng AND H. Yun, Sharpening of Jordan's inequality and its applications, J. Inequal. Pure Appl. Math. 7, 3 (2006), Article 102. 
[16] D. He And Y.-Z. HuAng, The extension of Redheffer inequalities in trigonometric functions, J. Foshan Univ. 30, 6 (2012), 37-44 (in Chinese).

[17] J.-L. Li AND Y.-L. LI, On the Strengthened Jordan's Inequality, J. Inequal. Appl. 2007, Article. ID 74328,8 pages.

[18] B. J. MALEŠEviĆ, One method for proving inequalities by computer, J. Inequal. Appl. 2007, Article ID 78691.

[19] Y. NishizaWA, Sharp Becker-Stark's type inequalities with power exponential functions, J. Inequal. Appl. 2015 (2015) 402, http://rd.springer.com/article/10.1186/s13660-015-0932-9/ fulltext.html.

[20] A. Y. ÖZBAN, A new refined form of Jordan's inequality and its applications, Appl. Math. Lett. 19 (2006), 155-160.

[21] R. RedHefFer, Problem 5642, Amer. Math. Monthy 76 (1969), 422.

[22] J. SÁndor And B. A. Bhayo, On an inequality of Redheffer, Miskolc Math. Notes, 16, 1 (1969), 475-482.

[23] S. B. STEČKIN, Some remarks on trigonometric polynomials, Uspekhi Matematicheskikh Nauk, vol. 10, no. 1 (63), (1955) 159-166 (in Russian).

[24] Z.-J. SUN AND L. ZHU, Simple proofs of the Cusa-Huygens-type and Becker-Stark-type inequalities, J. Math. Inequal. 7 (2013), 563-567.

[25] J. P. Williams, Solution of problem 5642, Amer. Math. Monthly 76 (1969) 1153-1154.

[26] S. H. WU, Sharpness and generalization of Jordan's inequality and its application, Taiwanese J. Math. 12 (2008), 325-336.

[27] S. H. Wu AND L. Debnath, A new generalized and sharp version of Jordan's inequality and its applications to the improvement of the Yang Le inequality, Appl. Math. Lett. 19 (2006), 1378-1384.

[28] S. H. WU AND L. DeBnath, A new generalized and sharp version of Jordan's inequality and its applications to the improvement of the Yang Le inequality, II, Appl. Math. Lett. 20 (2007), 532-538.

[29] S. H. WU AND L. DEBNATH, Jordan-type inequalities for differentiable functions and their applications, Appl. Math. Lett. 21 (2008), 803-809.

[30] S. H. WU AND H. M. SRIVASTAVA, A further refinement of a Jordan type inequality and its application, Appl. Math. Comput. 197 (2008), 914-923.

[31] L. YAng, Distribution of Values and New Research, Science Press, Beijing, 1982 (in Chinese).

[32] X. H. Zhang, G. D. WANG AND Y. M. CHU, Extensions and sharpenings of Jordan's and Kober's inequalities, J. Inequal. Pure Appl. Math. 7, 2 (2006), Article 63.

[33] C. J. ZhaO, Generalization and strengthen of Yang Le inequality, Mathematics Practice Theory 30 (2000), 493-497 (in Chinese).

[34] L. ZHU, Sharpening Jordan's inequality and Yang Le inequality, Appl. Math. Lett. 19 (2006), 240243.

[35] L. ZHU, Sharpening Jordan's inequality and Yang Le inequality, II, Appl. Math. Lett. 19 (2006), 990-994.

[36] L. ZHU, General forms of Jordan and Yang Le inequalities, Appl. Math. Lett. 22 (2009), 236-241.

[37] L. ZHU, Sharpening Redheffer-type inequalities for circular functions, App. Math. Lett. 22, 5 (2009), 743-748,

[38] L. ZHU, Sharp Becker-Stark-type inequalities for Bessel functions, J. Inequal. Appl. 2010, Article ID 838740, 4 pages.

[39] L. ZHU, A refinement of the Becker-Stark inequalities, Math. Notes 93 (2013), 421-425.

[40] L. Zhu AND J. K. HuA, Sharpening the Becker-Stark inequalities, J. Inequal. Appl. 2010, Article ID 931275, 4 pages.

[41] L. ZHU AND J. SUN, Six new Redheffer-type inequalities for circular and hyperbolic functions, Comput. Math. Appl. 56, 2 (2008) 522-529. 